\title{
Sistem Informasi Seleksi Pelatihan Kerja di PPKD Jakarta Timur
}

\author{
Andrian Erlangga ${ }^{1}$, Tuti Haryanti ${ }^{2}$, Yuyun Yuningsih ${ }^{3}$, Laela Kurniawati ${ }^{4}$ \\ Program Studi Sistem Informasi \\ Sekolah Tinggi Manajemen Informatika dan Komputer Nusa Mandiri \\ Jakarta Pusat \\ 11162783@nusamandiri.ac.id ${ }^{1}$,tuti@nusamandiri.ac.id ${ }^{2}$, \\ yuyun.ygg@nusamandiri.ac.id ${ }^{3,}{ }^{1 a e l a .1 k i @ n}$ nsamandiri.ac.id ${ }^{4}$
}

\begin{abstract}
Abstrak: Indonesia merupakan negara dengan tingkat pengangguran yang relaif tinggi, hal itu disebabkan oleh beberapa masalah, diantaranya yaitu, lulusan-lulusan yang tidak mempunyai kemampuan yang spesifik, oleh karena pemerintah perlu menjalankan program pelatihan kerja, agar setiap lulusan dapat mempunyai kemampuan yang spesifik di bidangnya masing-masing, dalam hal ini, instalnsi pemerintah yang bertanggung jawab adalah PPKD atau Pusat Pelatihan Kerja Daerah. Untuk menunjang proses seleksi calon peserta pelatihan, perlu dibuatkan sebuah sistem yang mampu menseleksi calon peserta dengan baik. Dalam hal ini, penulis merancang sebuah sistem informasi seleksi pelatihan kerja dengan menggunakan beberapa bahasa pemrograman dan framework yang dinilai bisa meng-handle pemrosesan data. Diantaranya yaitu, HTML, CSS, PHP dan Codeigniter sebagai frameworknya. Selain itu, penulis merancang alur sistemnya menggunakan diagram UML dan Data Modelling. Dengan komposisi teknologi tersebut, penulis menilai sistem yang akan dibuat dapat memenuhi kriteria yang dibutuhkan oleh instansi.
\end{abstract}

Kata kunci: Seleksi; Sistem Informasi; Pelatihan Kerja; PHP

\begin{abstract}
Abstrac: Indonesia is a country with a relatively high unemployment rate, it is caused by several problems, including namely, graduates who do not have specific abilities, because the government needs to carry out job training programs, so that each graduate can have specific abilities in their respective fields - in this case, the government installation responsible is PPKD or the Regional Job Training Center. To support the selection process of prospective trainees, a system should be able to select prospective participants well. In this case, the authors designed a job training selection information system using several programming languages and frameworks that were judged to be able to handle data processing. Among them, HTML, CSS, PHP and Codeigniter as the framework. In addition, the authors designed the flow of the system using UML diagrams and Data Modeling. With the composition of the technology, the authors assess the system that will be made can meet the criteria needed by the agency.
\end{abstract}

Keywords: Selection; Information System; Job Training; PHP 


\section{Pendahuluan}

Perkembangan teknologi yang sangat cepat telah mempengaruhi cara berkehidupan di era ini. Teknologi masuk kedalam berbagai macam aspek kehidupan, baik itu kehidupan bersosial, hingga mempengaruhi kehidupan dalam bekerja. Implementasi teknologi dalam kehidupan sangat membantu mempersingkat waktu dalam mengerjakan suatu hal. Salah satu contoh implementasinya adalah proses seleksi kerja atau pelatihan secara online.

Karyawan merupakan aset yang sangat penting bagi perusahaan atau organisasi, meskipun dengan berbagai macam perkembangan teknologi, tentunya hal itu tidak akan bisa berjalan tanpa ada karyawan yang menjalankannya. Hal tersebut tentunya merupakan tanggung jawab semua pihak termasuk pemerintah untuk membentuk generasi muda yang mempunyai kompetensi yang baik dibidangnya masing-masing, untuk itu, proses seleksi dan pelatihan yang baik tentunya akan berperan penting dalam dalam proses pembentukan sumber daya manusia yang kompeten.

Seleksi atau perekrutan adalah "langkah awal pelaksanaan rencana kepegawaian yang bertujuan untuk memperoleh tenaga kerja yang potensial dan berkualitas [1]". Dalam proses seleksi karyawan atau pelatihan, sebagian besar perusahaan masing menggunakan metode konvensional, tentunya hal tersebut dinilai kurang efektif di era ini, dikarenakan proses yang berbelit dan butuh waktu yang lama.

PPKD Jakarta Timur merupakan salah satu Unit Pelaksana Teknis pada bidang pelatihan kerja. PPKD Jakarta Timur secara administratif berada dibawah pembinaan Dinas Tenaga Kerja dan Transmigrasi Provinsi Daerah Khusus Ibukota Jakarta. Dalam proses seleksi peserta pelatihan kerja, PPKD Jakarta Timur masih menggunakan metode konvensional, yaitu metode seleksi manual, dimana dari mulai pendaftaran hingga pengumuman kelulusan masih dilakukan dengan cara datang langsung ke kantor PPKD Jakarta Timur, tentu saja hal itu kurang efektif, karena membutuhkan waktu proses yang cukup panjang, dan mengerahan banyak tenaga pegawai PPKD dalam memproses setiap data pendaftar yang masuk.

Organisasi menggunakan metode E-Recruitment karena "Selain menghemat biaya, brand organisasi dapat lebih dikenal dan memperbesar peluang mendapat calon karyawan yang sesuai kriteria (job specification) yang telah ditetapkan organisasi [2]”.

\section{Metode Penelitian}

Untuk memperoleh data-data yang diperlukan dalam penelitian ini, penulis menggunakan beberapa metode pengumpulan data yaitu Waterfall (Air Terjun).

Menurut Sukamto \& Shalahuddin (2015:28) mengemukakan bahwa model SDLC air terjun (waterfall) sering juga disebut model sekuensial (sequential linear) atau alur hidup klasik (classic life cycle). Model air terjun menyediakan pendekatan alur hidup perangkat lunak secara sekuensial atau terurut dimulai dari analisis, desain, pengodean, pengujian dan tahap pendukung (support).

a. Analisis Kebutuhan Perangkat Lunak

Melakukan analisa terhadap software yang terkait dengan proses bisnis seleksi. Analisa yang sesuai antara interface (log-in, tambah barang, daftar barang, barang masuk, peminjaman) dengan dokumen request perbaikan, daftar barang keluar-masuk, data peminjaman.

b. Desain

Membuat desain sistem dengan menggunakan Unified Modeling Language (UML) dan desain database menggunakan Entity Relationship Diagram (ERD) yang dapat 
membantu menyelesaikan masalah-masalah yang dihadapi pihak perusahaan serta melakukan pengembangan sistem yang sudah ada.

c. Pembuatan Kode Program

Konsep program yang akan dibuat adalah konsep pemrograman berbasis objek dengan menggunakan bahasa pemrograman Javascript, dan database MySQL.

d. Pengujian

Pengujian ini dilakukan untuk mengetahui apakah software yang dibuat telah sesuai dengan desainnya dan masih terdapat kesalahan atau tidak. Pada pengujian ini digunakan metode blackbox. Menguji apakah input (masukan) sesuai dengan output (hasil) yang diinginkan.

e. Pendukung (Support) atau Pemeliharaan (Maintance)

Support bertujuan untuk menjaga dan mengembangkan sistem yang dibuat dengan cara selalu melakukan pengamatan (maintenance) dan melakukan pembaharuan (upgrade) sistem dari segi hardware dan software agar tetap berjalan dengan baik.

\section{Hasil dan Pembahasan}

a. Analisa Kebutuhan Perangkat Lunak

Pada tahapan analisis bertujuan memodelkan masalah agar lebih mudah dipahami dan siap dirancang solusinya. Selama tahap ini, penulis mengamati sistem yang berjalan, mengidentifikasi kesempatan perbaikan dan menghasilkan konsep untuk sistem yang diharapkan menjadi lebih baik.

\section{Halaman Calon Peserta:}

A.1. Calon Peserta dapat melakukan registrasi online.

A.2. Calon Peserta dapat melakukan login.

A.3. Calon Peserta dapat mengisi form data diri.

A.4. Calon Peserta dapat memilih pelatihan.

A.5. Calon Peserta dapat mengikuti seleksi pelatihan.

\section{Halaman Petugas:}

B.1. Petugas dapat melakukan login.

B.2. Petugas dapat mengelola data lowongan pelatihan.

B.3. Petugas dapat mengelola data calon peserta.

B.4. Petugas dapat mengelola data seleksi.

B.5. Petugas dapat mengelola data hasil seleksi dengan metode profile matching.

B.6. Petugas dapat mencetak laporan.

\section{b. Desain}

Dalam tahap desain ini merupakan tahapan mendefinisikan proses serta kebutuhan sistem, mulai dari desain database, software architecture, user interface, code generation, testing dan support. 
Logical data model sistem adalah suatu proses untuk merancang model database suatu sistem, dapat dilihat pada Gambar 1, dalam model atau alur database sistem informasi seleksi pelatihan kerja ini terdapat 7 Entitas yang memiliki funginya masing-masing.

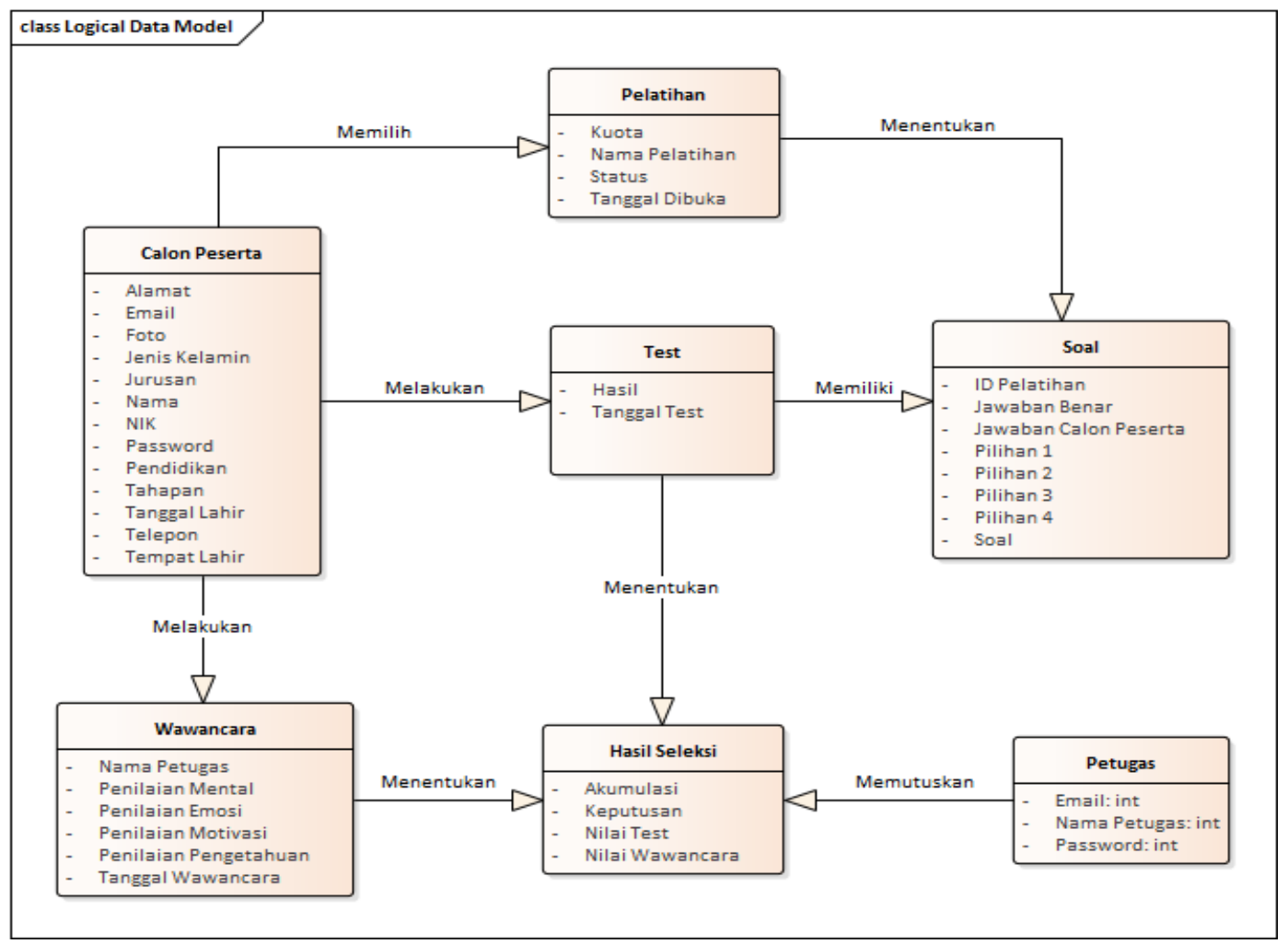

Gambar 1. Logical Data Model

Hasil perancangan sistem untuk tampilan menu login dapat dilihat pada Gambar 2. Pada menu login peserta harus memasukkan email dan password yang benar.

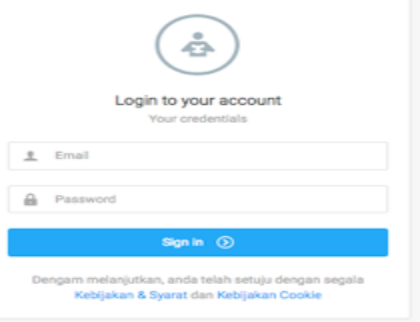

Gambar 2. User Interface Login 
Untuk registrasi, calon peserta di wajibkan untuk mengisi form berikut: Nama Lengkap, Alamat, Password, dan konfirmasi password. Setelah semua form terisi selanjutnya klik tombol Register. Tampilan bisa dilihat pada Gambar 3.

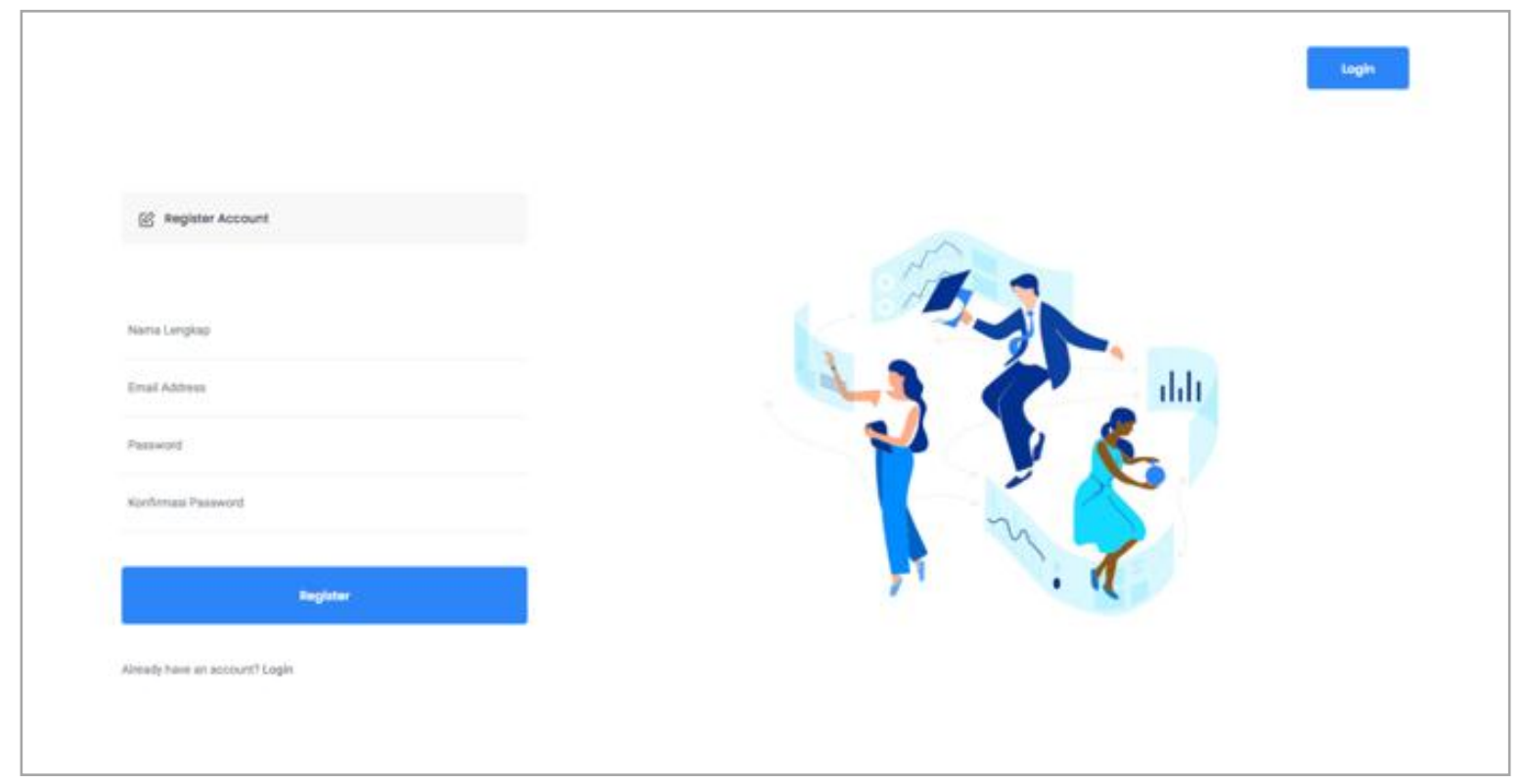

Gambar 3. User Interface Registrasi Calon Peserta

Tampilan hasil akumulasi nilai dapat dilihat pada Gambar 4, dimana pada tabel akumulasi nilai terdapat kolom nama, nilai test, nilai wawancara, dan akumulasi nilai.

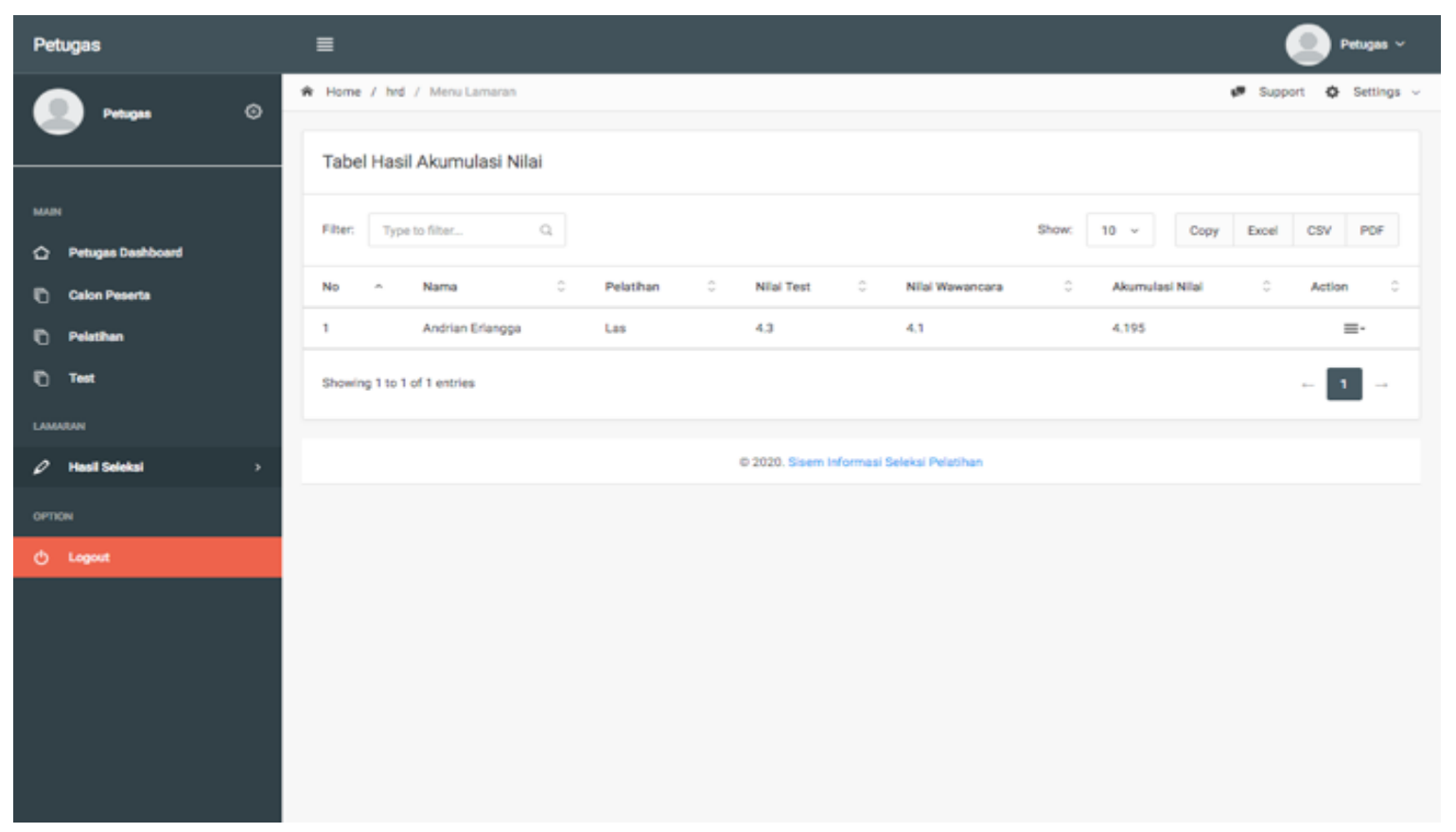

Gambar 4. User Interface Akumulasi Hasil 


\section{c. Testing}

Pengujian terhadap program yang menggunakan blackbox testing yang fokus terhadap proses masukkan dan keluaran program dapat dilihat pada Tabel 1.

Tabel 1. Hasil uji coba Blackbox

\begin{tabular}{|c|c|c|c|c|}
\hline Skenario & Test Case & Yang Diharapkan & Hasil & Kesimpulan \\
\hline $\begin{array}{l}\text { Mengosongkan } \\
\text { semua isian } \\
\text { data registrasi, } \\
\text { kemudian klik } \\
\text { tombol "Login" }\end{array}$ & $\begin{array}{l}\text { Email: } \\
\text { (kosong) } \\
\text { Password: } \\
\text { (kosong) }\end{array}$ & $\begin{array}{l}\text { Sistem akan menolak } \\
\text { akses dengan } \\
\text { menampilkan pesan } \\
\text { "data login tidak boleh } \\
\text { kosong" }\end{array}$ & $\begin{array}{c}\text { Sesuai } \\
\text { harapan }\end{array}$ & Valid \\
\hline $\begin{array}{l}\text { Mengisi nama } \\
\text { dan username, } \\
\text { email dan } \\
\text { password } \\
\text { kosong, } \\
\text { kemudian klik } \\
\text { tombol "Login" }\end{array}$ & $\begin{array}{l}\text { Email: } \\
\text { (kosong) } \\
\text { Password: } \\
\quad \text { (isi) }\end{array}$ & $\begin{array}{l}\text { Sistem akan menolak } \\
\text { akses dengan } \\
\text { menampilkan pesan } \\
\text { "data login belum } \\
\text { lengkap" }\end{array}$ & $\begin{array}{c}\text { Sesuai } \\
\text { harapan }\end{array}$ & Valid \\
\hline $\begin{array}{l}\text { Mengisi nama, } \\
\text { username, } \\
\text { email dan } \\
\text { password isi, } \\
\text { kemudian klik } \\
\text { tombol "Login" }\end{array}$ & $\begin{array}{l}\text { Email: (isi) } \\
\text { Password: } \\
\quad \text { (isi) }\end{array}$ & $\begin{array}{l}\text { Sistem menerima data } \\
\text { login dan sistem } \\
\text { menampilkan halaman } \\
\text { login Calon Peserta }\end{array}$ & $\begin{array}{c}\text { Sesuai } \\
\text { harapan }\end{array}$ & Valid \\
\hline
\end{tabular}

\section{Kesimpulan}

Dengan menerapkan sistem informasi seleksi calon peserta maka dapat meminimalisir waktu dan biaya dalam proses seleksi peserta pelatihan baru. Pemrosesan informasi lowongan seleksi lebih cepat dan efisien. Membantu untuk mendapatkan calon peserta terbaik yang sesuai dengan posisi pelatihan yang dibutuhkan. Meskipun proses seleksi sudah berbasis sistem, namun masih memiliki kekurangan seperti belum adanya sistem komunikasi antara calon peserta dan petugas, sehingga calon peserta tidak bisa bertanya mengenai hal-hal yang kurang dimengerti. 


\section{Daftar Pustaka}

R. I. Desanti, C. F. Supit, and A. E. Widjaja, "Aplikasi Perekrutan dan Penilaian Karyawan Berbasis Web Pada PT . XYZ," Ultim. InfoSys, ISSN 2085-4579, vol. VIII, no. 2, pp. 74-80, 2017.

K. Dwi Nanda and A. Prasetya, "Eketifitas Penerapan Metode Rekrutmen Online (ERecruitment) Pada PT. Industri Kereta Api (INKA) - Jawa Timur," J. Adm. Bisnis, vol. 53, no. 1, pp. 96-104, 2017, [Online]. Available: administrasibisnis.studentjournal.ub.ac.id.

R. Asmara, "Sistem Informasi Pengolahan Data Penanggulangan Bencana Pada Kantor Badan Penanggulangan Bencana Daerah (BPBD) Kabupaten Padang Pariaman," vol. 3, no. 2, 2016.

F. Fatmawati and J. Munajat, "Implementasi Model Waterfall Pada Sistem Informasi Persediaan Barang Berbasis Web (Studi Kasus: PT.Pamindo Tiga T)," J. Media Inform. Budidarma, vol. 2, no. 2, pp. 1-9, 2018, doi: 10.30865/mib.v2i2.559.

H. S. Asfinoza, Shinta Puspasari, "Sistem Informasi Penjualan Pupuk Berbasis Web," vol. 14, no. 1, pp. 1-6, 2018.

R. A. Pascapraharastyan, A. Supriyanto, and P. Sudarmaningtyas, "Rancang Bangun Sistem Informasi Manajemen Arsip Rumah Sakit Bedah Surabaya Berbasis Web," Sist. Inf., vol. 3, no. 1, pp. 72-77, 2015.

E. W. Firdhayanti and J. Carter, "Rancang Bangun Sistem Informasi Simpan Pinjam Karyawan Menggunakan Metode Object Oriented Programming (Studi Kasus: PT. Arta Buana Sakti Tangerang)," vol. XIII, no. 2, pp. 63-71, 2016.

O. Pahlevi, A. Mulyani, and M. Khoir, "Sistem Informasi Inventori Barang Menggunakan Metode Object Oriented Din PT . Livaza Teknologi Indonesia Jakarta," J. Prosisko, vol. 5, no. 1, pp. 27-35, 2018.

Megawati and I. R. A. Putra, "Rancang Bangun Sistem Informasi Akuntansi Berbasis Web ( Studi Kasus Pada PT. Kalber )," J. Sains, Teknol. dan Ind., vol. 15, no. 2, pp. 98-104, 2018.

A. Hendini, "Pemodelan UML Sistem Informasi Monitoring Penjualan Dan Stok Barang (Studi Kasis: Distro Zhezha Pontianak)," Junal Khatulistiwa, vol. 4, no. 2, pp. 201205, 2016, doi: 10.2135/cropsci1983.0011183x002300020002x.

I. K. G. Sudiartha, I. N. E. Indrayana, and I. W. Suasnawa, "Membangun Struktur Realtime Database Firebase Untuk Aplikasi Monitoring Pergerakan Group Wisatawan," J. Ilmu Komput., vol. 11, no. 2, p. 96, 2018, doi: 10.24843/jik.2018.v11.i02.p04.

Sutabri, "perancangan sistem informasi pengolahan data PKL pada divisi humas PT pegadaian," J. Infra tech, vol. 2, no. 2, pp. 12-26, 2018, [Online]. Available: http://journal.amikmahaputra.ac.id/index.php/JIT/article/download/33/25.

W. N. Cholifah, Y. Yulianingsih, and S. M. Sagita, "Pengujian Black Box Testing pada Aplikasi Action \& Strategy Berbasis Android dengan Teknologi Phonegap," STRING (Satuan Tulisan Ris. dan Inov. Teknol., vol. 3, no. 2, p. 206, 2018, doi: 10.30998/string.v3i2.3048. 